\title{
Comparative study of the price penalty factors approaches for Bi-objective dispatch problem via PSO
}

\author{
Mohammed Amine Meziane' ${ }^{1}$, Youssef Mouloudi², Abdelghani Draoui ${ }^{3}$ \\ 1,2,3 Departement of Electrical Engineering, University of Tahri Mohammed, Bechar, Algeria \\ ${ }^{1,2,3}$ Smart Grids and Renewable Energies Laboratory (SGRE), Algeria
}

\begin{tabular}{l} 
Article Info \\
\hline Article history: \\
Received Jul 28, 2018 \\
Revised Jan 24, 2020 \\
Accepted Feb 2, 2020 \\
\hline
\end{tabular}

Keywords:

Bi-objective dispatch problem Combined economic emission dispatch

Particle swarm optimization

Price penalty factor

Real West Algeria electrical network

\begin{abstract}
One of the main objectives of electricity dispatch centers is to schedule the operation of available generating units to meet the required load demand at minimum operating cost with minimum emission level caused by fossil-based power plants. Finding the right balance between the fuel cost the green gasemissionsis reffered as Combined Economic and Emission Dispatch (CEED) problem which is one of the important optimization problems related the operationmodern power systems. The Particle Swarm Optimization algorithm (PSO) is a stochastic optimization technique which is inspired from the social learning of birds or fishes. It is exploited to solve CEED problem. This paper examines the impact of six penalty factors like "Min-Max", "Max-Max", "Min-Min", "Max-Min", "Average" and "Common" price penalty factors for solving CEED problem. The Price Penalty Factor for the CEED is the ratio of fuel cost to emission value. This bi-objective dispatch problem is investigated in the Real West Algeria power network consisting of 22 buses with 7 generators. Results prove capability of PSO in solving CEED problem with various penalty factors and it proves that Min-Max price penalty factor provides the best compromise solution in comparison to the other penalty factors.
\end{abstract}

Copyright $\odot 2020$ Institute of Advanced Engineering and Science. All rights reserved.

\section{Corresponding Author:}

Mohammed Amine Meziane,

Faculty of Science and Technology, Departement of Electrical Engineering,

Smart Grids and Renewable Energies Laboratory (SGRE),

University of Tahri Mohammed,

BP 417, 08000 Bechar, Algeria.

Email: aminemohmeziane@gmail.com

\section{INTRODUCTION}

Electric utility systems are interconnected to achieve high operating efficiency and to produce cheap electricity with minimum production cost, maximum reliability, and better operating conditions [1]. The optimal power flow problem (OPF) is an important tool in operation and control of large modern power systems, it was first discussed by Carpentier in 1962 [2], the main purpose of OPF is to find the optimal output power of generators to minimize the total generation cost and satisfy the equality and inequality constraints. Operating at absolute minimum cost can no longer be the only criterion for dispatching electric power due to increasing concern over the environmental issues. The generation of electricity from fossil fuel resources releases several contaminants, such as $\mathrm{SOx}, \mathrm{NOx}$ and $\mathrm{CO} 2$ into the atmosphere [3]. In this paper the used term Economic Dispatch Problem (ED) is the short-term which refers to the determination of the optimal output of a number of electricity generation facilities.

The aim of every generating station is to produce electricity at the lowest possiblefuel consumption and emission rates, but these two constraints cannot be metsimultaneously. Nowadays, the demand for energy is increasing at a high pace, which makes it highly crucial to run generators at very minimal cost. This is the main goal of an Economic Dispatch Problem. With the exceptional production of carbon emissions by 
thermal power plants [4], the environmental issues has become a big concern which has to be addressedto mitigate the effects of pollution and hence rectify problem of global warming. Therefore, production of electricity with an optimized costat a lower green gas emmissionsacts as two vital parts of economic dispatch problem. Production at the minimum cost result in a relatively high amount of emissions. Similarly, ensuring minimum gas emissions limits the production of utilities running on fossil fuels. In order to find a right balance in the present tradeoff, this optimization problem can be modelled asa multi-objective function (Economic/Emission) which involves minimization of the cost function of producing electrical energy and minimization of the gas emission function, by satisfying the constraints of both functions.

In the modeling of the bi-objective economic dispatch problem, the presentcomparative study examines different types of the constraints and various types of price penalty factors. The following parameters are considered:

a. Fuel cost and emission functions are modelled as second order polynomial function for both.

b. The following types of price penalty factors are used for the multi-objective dispatch problem:

- Min-Max price penalty factor

- Max-Max price penalty factor

- Min-Min price penalty factor

- Max-Min price penalty factor

- Average price penalty factor

- Common price penalty factor

c. Type of constraints to be satisfied are:

- Load/supply balance

- Minimum/maximum limits of the energy produced by the generators

- Transmission line losses

In order to overcome the above illustrated drawbacks, heuristic methodologies have been under research for solving CEED problem. In the past the traditional methods used to solve this economic load dispatch problem are the Lambda iteration method, Gradient, Newton, linear programming and interior point method. Recently, meta-heuristic techniques such as Simulated Annealing, Genetic Algorithm (GA), Particle Swarm Optimization (PSO), and Tabu search algorithm are used to solve this problem [5]. In this paper, the Particle Swarm Optimization based-approach is proposed to solve the CEED problem. In order to facilitate the search for the optimized solution, the price penalty factor is used to convert the bi-objective CEED problem into a single objective function. The proposed method has been examined and tested on a real grid in west Algeria which consists of a 22-bus system of 220 Kvvoltage level. Satisfactory simulation results show the effectiveness of the proposed algorithm.

\section{MATHEMATICAAL FORMULATION OF CEED PROBLEM}

The bi-objective function for CEED problem [6-12] is given as follows: $C E E D=\operatorname{Min}($ Generation cost $)+$ penalty factor $\times \operatorname{Min}($ Emission value $)$

$$
F_{c}=\operatorname{Min} \sum_{i=1}^{n G} F_{i}\left(P_{G i}\right)=\operatorname{Min} \sum_{i=1}^{n G}\left(a_{i} P_{G i}^{2}+b_{i} P_{G i}+c_{i}\right)
$$

where $F_{c}$ is the total fuel cost of the system is, $n_{g}$ is the number of generators, $P_{G i}$ is real power generation of a generator unit $i$, and $a_{i}, b_{i}$ and $c_{i}$ are the cost coefficients of the $i^{\text {th }}$ generating unit.

$$
E_{T}=\operatorname{Min} \sum_{i=1}^{n G}\left(\alpha_{i} P_{G i}^{2}+\beta_{i} P_{G i}+\gamma_{i}\right)
$$

where, $E_{T}$ is total emission; $\alpha_{i}, \beta_{i}, \gamma_{i}$ are emission coefficients of generating unit $i$ in $\left[\mathrm{kg} / \mathrm{MW}^{2} \mathrm{~h}\right],[\mathrm{kg} / \mathrm{MWh}]$ and $[\mathrm{kg} / \mathrm{h}]$ respectively. Price penalty factor $h_{i}$ is used to convert the bi-objective CEED optimization problem into a single objective [6-13] problem:

$$
F_{T}=\sum_{i=1}^{G g}\left[\left(\left(a_{i} P_{G i}^{2}+b_{i} P_{G i}+c_{i}\right)\right)+h_{i}\left(\left(\alpha_{i} P_{G i}^{2}+\beta_{i} P_{G i}+\gamma_{i}\right)\right)\right]
$$

where, $\mathrm{F}_{\mathrm{T}}$ is total CEEDfuel cost; $\mathrm{h}_{\mathrm{i}}$ is price penalty factor.

\section{PRICE PENALTY FACTORS (PPF)}

The PPF [6, 11, 13-23] for CEED problem is formulated taking the ratio fuel cost and emission value of the corresponding generators as follows: 
- Min-Max price penalty factor is described as:

$$
h_{i}=\frac{\mathrm{a}_{\mathrm{i}} \mathrm{P}_{\mathrm{Gi}, \text { min }}^{2}+\mathrm{b}_{\mathrm{i}} \mathrm{P}_{\mathrm{Gi}, \min }+\mathrm{c}_{\mathrm{i}}}{\alpha_{\mathrm{i}} \mathrm{P}_{\mathrm{Gi}, \text { max }}^{2}+\beta_{\mathrm{i}} \mathrm{P}_{\mathrm{Gi}, \max }+\gamma_{\mathrm{i}}}
$$

- Max-Max price penalty factor is described as:

$$
h_{i}=\frac{\mathrm{a}_{\mathrm{i}} \mathrm{P}_{\mathrm{Gi}, \text { max }}^{2}+\mathrm{b}_{\mathrm{i}} \mathrm{P}_{\mathrm{Gi}, \text { max }}+\mathrm{c}_{\mathrm{i}}}{\mathrm{d}_{\mathrm{i}} \mathrm{P}_{\mathrm{Gi}, \text { max }}^{2}+\mathrm{e}_{\mathrm{i}} \mathrm{P}_{\mathrm{Gi}, \max }+\gamma_{\mathrm{i}}}
$$

- Min-Min price penalty factor is described as:

$$
h_{i}=\frac{\mathrm{a}_{\mathrm{i}} \mathrm{P}_{\mathrm{Gi}, \min }^{2}+\mathrm{b}_{\mathrm{i}} \mathrm{P}_{\mathrm{Gi}, \min }+\mathrm{c}_{\mathrm{i}}}{\alpha_{\mathrm{i}} \mathrm{P}_{\mathrm{Gi}, \min }^{2}+\beta_{\mathrm{i}} \mathrm{P}_{\mathrm{Gi}, \min }+\gamma_{\mathrm{i}}}
$$

- Max-Min price penalty factor is described as:

$$
h_{i}=\frac{\mathrm{a}_{\mathrm{i}} \mathrm{P}_{\mathrm{Gi}, \text { max }}^{2}+\mathrm{b}_{\mathrm{i}} \mathrm{P}_{\mathrm{Gi}, \text { max }}+\mathrm{c}_{\mathrm{i}}}{\alpha_{\mathrm{i}} \mathrm{P}_{\mathrm{Gi}, \text { min }}^{2}+\beta_{\mathrm{i}} \mathrm{P}_{\mathrm{Gi}, \min }+\gamma_{\mathrm{i}}}
$$

- Average price penalty factor is formulated as:

$$
h_{A V E R A G E i}=\frac{\sum_{1}^{4} h_{i}}{4}
$$

- Common price penalty factor is formulated as:

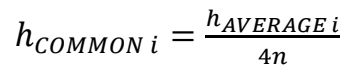

where: $\mathrm{n}$ is operational generating unit.

\section{CONSTRAINTS}

\subsection{Power balance constraints [24]}

Where, $\mathrm{P}_{\mathrm{G}}, \mathrm{P}_{\text {Demand }}$ and $\mathrm{P}_{\mathrm{Loss}}$ are the total generated power, load demand and transmission line loss of the system respectively. Transmission line loss constraint can be given as, [25]:

$$
\mathrm{P}_{\mathrm{G}}=\sum_{\mathrm{i}=1}^{\mathrm{n}} \mathrm{P}_{\mathrm{i}}=\mathrm{P}_{\text {Demand }}+\mathrm{P}_{\text {Loss }}
$$

where, $P_{i}$, and $P_{j}$ is the active power of unit $i^{i h}$ and $j^{i h}$ respectively. $B_{i j}, B_{0 i}$ and $B_{00}$ is the transmission loss coefficients.

$$
\mathrm{P}_{\mathrm{L}}=\sum_{\mathrm{i}=1}^{\mathrm{n}} \sum_{\mathrm{i}=\mathrm{j}}^{\mathrm{n}} \mathrm{P}_{\mathrm{i}} \mathrm{B}_{\mathrm{ij}} \mathrm{P}_{\mathrm{j}}+\sum_{\mathrm{i}=1}^{\mathrm{n}} \mathrm{B}_{0 \mathrm{i}} \mathrm{P}_{\mathrm{i}}+\mathrm{B}_{00}
$$

\subsection{Generator limits} is given as:

The power output of each generator is restricted by minimum and maximum power limits,

$$
\mathrm{P}_{\mathrm{Gi} \text { min }} \leq \mathrm{P}_{\mathrm{Gi}} \leq \mathrm{P}_{\mathrm{Gi} \max }
$$

\section{PARTICAL SWARM OPTIMIZATION ALGORITHM}

Particle swarm optimization PSO is a population-based optimization technique which was first introduced by Kennedy and Eberhart in 1995 [26], inspired by social behavior of bird flocking or fish schooling in search of food.The most important prominent features of PSO, compared to other existing heuristic optimization strategies such as genetic algorithm, are its easy implementation, there are few parameters to adjust and computation efficiency. In a PSO system, particles fly around in a multidimensional search space. During flight, each particle adjusts its trajectory towards its own previous best position this value is called $\left(\mathrm{P}_{\text {best }}\right)$, and towards the best previous position attained by any member of its neighborhood or

Comparative study of the price penalty factors approaches for Bi-objective dispatch ... (Youssef Mouloudi) 
globally, the whole swarm this value is called $\left(G_{\text {best }}\right)$ [27-32]. The two equations which are used in PSO are velocity update equation (13) and position update equations (14). These are to be modified at each time step, of PSO algorithm to converge the optimum solution.

$$
\begin{aligned}
& \mathrm{V}_{\mathrm{i}}(\mathrm{t}+1)=\omega \mathrm{V}_{\mathrm{i}}(\mathrm{t})+\mathrm{c}_{1} \mathrm{r}_{1}\left[\text { Pbest }_{\mathrm{i}}(\mathrm{t})-\mathrm{X}_{\mathrm{i}}(\mathrm{t})\right]+\mathrm{c}_{2} \mathrm{r}_{2}\left[\text { Gbest }_{\mathrm{i}}(\mathrm{t})-\mathrm{X}_{\mathrm{i}}(\mathrm{t})\right] \\
& X_{i}(t+1) X_{i}(t)+V_{i}(t+1)
\end{aligned}
$$

Where, ${ }^{i}$ is the particle index; ${ }^{\omega}$ is the inertia coefficient; are acceleration coefficients $0 \leq c_{1}, c_{2} \leq 2, r_{1}, r_{2}$ are random values, $0 \leq r 1, r_{2} \leq{ }_{\text {regenerated every velocity }} c_{1}, c_{2}$ update; $V_{i}$ is the particles velocity at time $\mathrm{t} ; X_{i}$ is the particles position at time $\mathrm{t}$; Pbest is the particles individual best solution as of time $\mathrm{t}$; ${ }^{G}$ best is the swarms best solution as of time $t$.

\section{SIMULATION RESULTS AND ANALYSIS}

The west algerian power network is a 22 bus system with 7production units. This latter is considered in an attempt to solve the CEED problem using "Min-Max", "Max-Max", "Min-Min", "Max-Min", "Average" and "Common" price penalty factors. The test system consists of 7 thermal units, 15 load buses and 31 transmission lines, 03compensator VARSTATIC SVC [3* (+40Mvar and )10Mvar)]. The total system demand is $856 \mathrm{MW}$. The data for the considering test system is shown in Table 1. The real power limits of the generators, fuel cost coefficients are also given in the Table 1. Programming of the CEED using the PSO method has been applied by using MATLAB software, tested on a CORE i5, personal computer with 2.20 GHz and 4 GO RAM. Table 2 show solution of CEED problem with different price penalty factors such as "Min-Max", "Max-Max", "Min-Min", "Max-Min", Average and Common. Table 3 compares the results obtained with all six penalty factors. As illustrated in Table 2 the results show an acceptable improvement in the fuel cost, and total fuel cost CEED of the system when using the Min-Max price penalty factor compared to other penalty factors. The emission value is less when using Max-Max price penalty factor in comparison with the other penalty factors. The Max-Min price penalty factor is better in terms of the lowest transmission loss compared to other penalty factors.

Table 1.22 bus system data

\begin{tabular}{cccccc}
\hline Generator & \multicolumn{2}{c}{ Generator limits $[\mathrm{MW}]$} & \multicolumn{4}{c}{ Fuel cost coefficients } \\
Numbers & $P_{\min }[\mathrm{MW}]$ & $P_{\max }[\mathrm{MW}]$ & $a_{i}\left[\$ / \mathrm{MW}^{2} \mathrm{~h}\right]$ & $b_{i}[\$ / \mathrm{MWh}]$ & $c_{i}[\$ / \mathrm{h}]$ \\
\hline 1 & 100 & 500 & 0.007 & 7.5 & 240 \\
2 & 50 & 200 & 0.008 & 7 & 200 \\
3 & 80 & 300 & 0.0085 & 7.5 & 220 \\
4 & 50 & 150 & 0.009 & 7 & 200 \\
5 & 50 & 200 & 0.009 & 9 & 220 \\
6 & 50 & 120 & 0.0075 & 10 & 190 \\
7 & 10 & 80 & 0.009 & 6.3 & 180 \\
\hline
\end{tabular}

\begin{tabular}{|c|c|c|c|c|c|c|c|}
\hline Price Penalty Factors & $\begin{array}{l}\text { Data } \\
\text { From } \\
\text { SONELG } \\
\text { AZ [30] }\end{array}$ & Min-Max & Max-Max & Min-Min & Max-Min & Average & Common \\
\hline$P_{1}[\mathrm{MW}]$ & 200 & 100.0000 & 100.0000 & 100.0000 & 100.0000 & 100.0000 & 100.0000 \\
\hline$P_{2}[\mathrm{MW}]$ & 200 & 206.2277 & 186.6597 & 246.9342 & 210.3191 & 164.5518 & 185.9998 \\
\hline$P_{3}[\mathrm{MW}]$ & 300 & 188.3073 & 219.3888 & 224.8282 & 191.1794 & 257.3631 & 236.7597 \\
\hline$P_{4}[\mathrm{MW}]$ & 80 & 130.3337 & 96.3901 & 138.6912 & 141.6869 & 56.5279 & 60.8637 \\
\hline$P_{5}[\mathrm{MW}]$ & 100 & 124.7016 & 124.0204 & 65.8667 & 60.0516 & 135.4592 & 105.7232 \\
\hline$P_{6}[\mathrm{MW}]$ & 100 & 88.4415 & 86.7610 & 63.0696 & 109.6222 & 73.1928 & 104.4470 \\
\hline$P_{7}[\mathrm{MW}]$ & 10 & 19.5432 & 50.2276 & 27.0108 & 43.4842 & 73.6464 & 83.2097 \\
\hline Power Loss [MW] & 21.4 & 20.882 & 20.175 & 20.087 & 17.409 & 21.550 & 19.049 \\
\hline Total output [MW] & 990 & 857.5555 & 863.4476 & 866.4007 & 856.3434 & 860.7412 & 877.0031 \\
\hline Power demand [MW] & 856 & 856 & 856 & 856 & 856 & 856 & 856 \\
\hline Generation cost $[\$ / h]$ & 9104.44 & 8892.0 & 8899.4 & 9089.8 & 8904.5 & 8909.5 & 9040 \\
\hline Emission $[\mathrm{Kg} / \mathrm{h}]$ & $*$ & 1096.1 & 1078.1 & 1228.9 & 1196.5 & 1101.4 & 1225.5 \\
\hline Total cost $[\$ / \mathrm{h}]$ & $*$ & 10903 & 14406 & 18985 & 36863 & 32346 & 40640 \\
\hline Temps [S] & $*$ & 0.095112 & 0.106198 & 0.080914 & 0.084423 & 0.096332 & 0.096956 \\
\hline
\end{tabular}

Table 2. Solution of CEED problem using PSO with various price penalty factors 
Table 3. Comparison of simulation results obtained from "Min-Max", "Max-Max", "Min-Min”, "Max-Min", "Average","Common" price penalty factors

\begin{tabular}{lllllll}
\hline Criterion & $\begin{array}{l}\text { Min-Max } \\
\text { price penalty } \\
\text { factor }\end{array}$ & $\begin{array}{l}\text { Max-Max } \\
\text { price penalty } \\
\text { factor }\end{array}$ & $\begin{array}{l}\text { Min-Min } \\
\text { price penalty } \\
\text { factor }\end{array}$ & $\begin{array}{l}\text { Max-Min } \\
\text { price penalty } \\
\text { factor }\end{array}$ & $\begin{array}{l}\text { Average } \\
\text { price penalty } \\
\text { factor }\end{array}$ & $\begin{array}{l}\text { Common } \\
\text { price penalty } \\
\text { factor }\end{array}$ \\
\hline Power Loss $[\mathrm{MW}]$ & $100 \%$ & $96.61 \%$ & $96.19 \%$ & $\mathbf{8 3 . 3 7 \%}$ & $103.19 \%$ & $93.03 \%$ \\
Generation $\operatorname{cost}[\$ / \mathrm{h}]$ & $\mathbf{1 0 0 \%}$ & $100.10 \%$ & $102.22 \%$ & $100.14 \%$ & $100.19 \%$ & $100.23 \%$ \\
Emission $[\mathrm{Kg} / \mathrm{h}]$ & $100 \%$ & $\mathbf{9 8 . 3 6 \%}$ & $112.12 \%$ & $109.16 \%$ & $100.48 \%$ & $103.52 \%$ \\
Total $\operatorname{cost}[\$ / \mathrm{h}]$ & $\mathbf{1 0 0 \%}$ & $132.13 \%$ & $174.12 \%$ & 338.09 & $296.67 \%$ & $652.79 \%$ \\
\hline
\end{tabular}

Figure 1 show clearly that the convergence profile obtained by PSO algorithm of functions such as CEED total cost, generation cost, emission cost and transmission loss when using Min-Max, Max-Max, Min-Min, Max-Min, average and common price penalty factors is faster and more effective, which proves that the proposed algorithm has more ability to find the optimal points in a search space compared with data provided by SONELGAZ, the company which is in charge of operating the above mentioned grid of west of Algeria [30].

From Figure 1(a), the variation of CEED fuel cost values of the bi-objective dispatch problem using Min-Max price penalty factor are the lowest compared to other penalty factors. Similarly, the variation of fuel cost values of the bi-objective dispatch problem using Min-Max price penalty factor are the lowest compared to other penalty factors, see Figure 1(b). Likewise, according to Figure 1(c) the variation of emission values of the bi-objective dispatch problem using Max-Max price penalty factor has minimum pollution control compared to other pnalty factors. Finally, From Figure 1(d) the variation of power lossvalues of the bi-objective dispatch problem using Max-Min price penalty factor has lowest transmission power loss compared to other penalty factors.

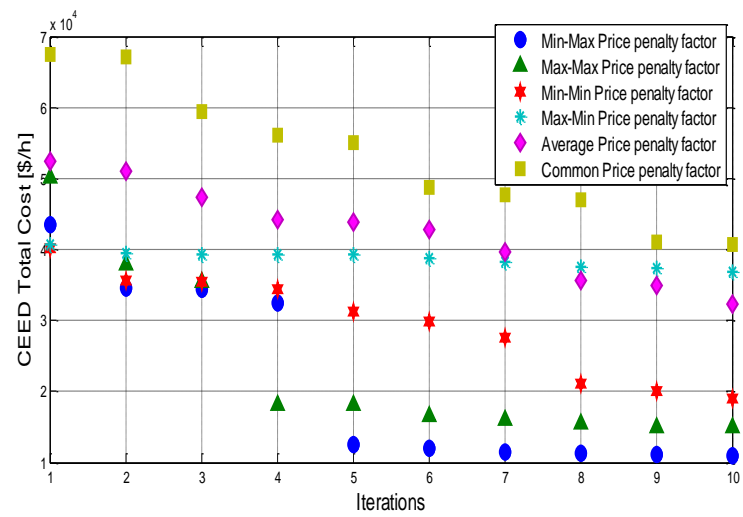

(a)

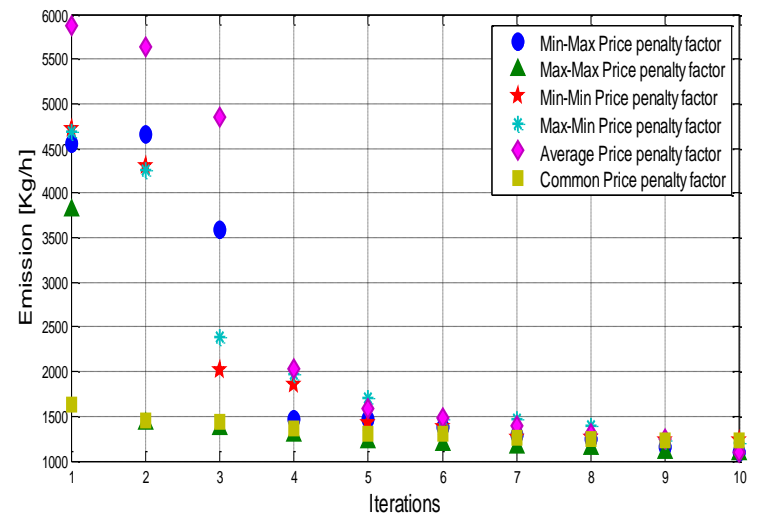

(c)

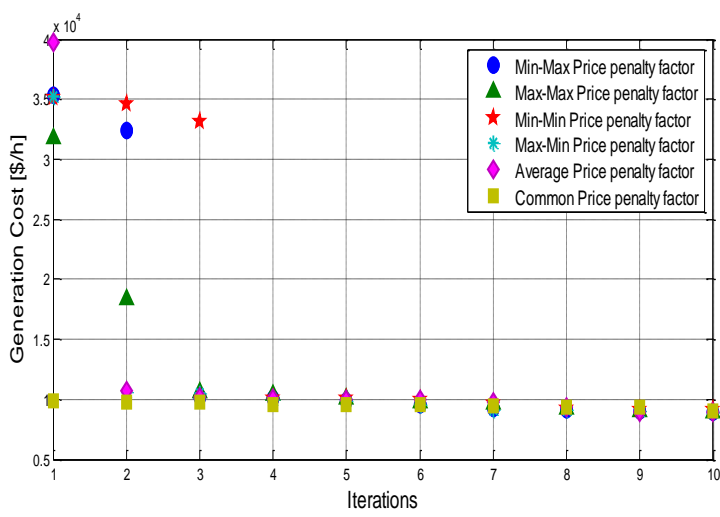

(b)

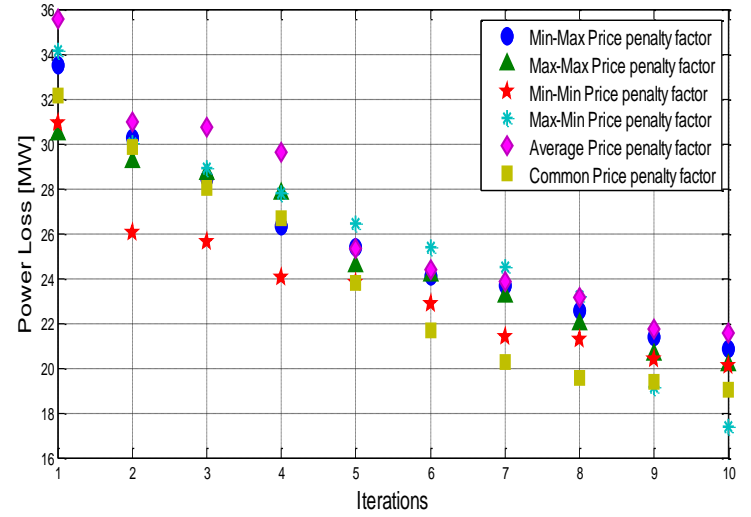

(d)

Figure 1. Convergence curve for functions such as, (a) CEED (comparison of CEED total cost using various price penalty factors), (b) fuel cost (comparison of generation cost usingvarious price penalty facteur), (c) emission value (comparison of emission value using various price penalty facteur), (d) power loss (comparison of power loss using variousprice penalty facteur) 


\section{CONCLUSION}

In this paper, the impact of price penalty factors on the solution of the bi-objective power system economic dispatch optimization problem is examined on electric grid of west algeria which consists of 22-Bus system. The Particle Swarm Optimization algorithm is proposed for solving the combined economic emission dispatch problem. On the basis of results obtained some conclusions are made: the simulation results show that Min-Max price penalty factor yields a minimum generation cost for bi-objective power dispatch problem. The results show that theminimum emission values are less in Max-Max price penalty factor compared to other penalty factors. The Max-Min price penalty factor is better in terms of the lowest transmission loss compared to other penalty factrors.

In Summary, it has been shown that the minimum overall cost for the bi-objective power system dispatch optimization problem can be obtained using Min-Max Price penalty factor. From Table 2 the CEED fuel cost values are significantly lower with Min-Max price penalty factor by $32.13 \%$ in comparison to the solution using Max-Max price penalty factor. The results also show that the emission values are less in Max-Max price penalty factor by $1.68 \%$ when compared to Min-Max price penalty factor.

\section{ACKNOWLEDGEMENTS}

Authors would like to thank the heads of Laboratory of Analysis, Control andOptimization of Electro-Energetic Systems (CAOSEE) and Laboratory of Smart Grids \& Renewable Energies (ENERGARID) at the university TAHRI Mohammed, Béchar (Algeria).

\section{REFERENCES}

[1] Senthil Krishnamurthy, Raynitchka Tzoneva. "Decomposition-Coordinating Method for Parallel Solution of a Multi Area Combined Economic Emission Dispatch Problem," International Journal of Electrical and Computer Engineering (IJECE), vol. 6, no. 5, pp. 2048-2063, October 2016.

[2] H. Wang, C. E. Murillo-Sanchez, R. D. Zimmerman and R. J. Thomas, "On Computational Issues of Market-Based Optimal Power Flow," in IEEE Transactions on Power Systems, vol. 22, no. 3, pp. 1185-1193, Aug. 2007.

[3] Mohammed Amine Meziane, Youssef Mouloudi, "An Effective Non-Traditional Algorithm for Solving the Problem of Optimal Power Flow with Minimum Environmental Pollution Using Price Penalty Factors," International Journal of Control and Automation, vol. 11, no. 2, pp. 55-74, 2018

[4] Faseela C. K., H. Vennila, "Economic and Emission Dispatch using Whale Optimization Algorithm (WOA)," International Journal of Electrical and Computer Engineering (IJECE), vol. 8, no. 3, pp. 1297-1304, June 2018.

[5] S. Dhanalakshmi, S. Kannan, K. Mahadevan and S. Baskar, "Application of modified NSGA-II algorithm to Combined Economic and Emission Dispatch problem," International Journal of Electrical Power \& Energy Systems, vol. 33, no. 4, pp. 992-1002, May 2011.

[6] S. Hemamalini and S. P. Simon, "Maclaurin series-based Lagrangian method for economic dispatch with valvepoint effect," in IET Generation, Transmission \& Distribution, vol. 3, no. 9, pp. 859-871, September 2009.

[7] Binod Shaw, V. Mukherjee, S. P. Ghoshal, "A novel opposition-based gravitational search algorithm for combined economic and emission dispatch problems of power systems," International Journal of Electrical Power \& Energy Systems, vol 35, no. 1, pp 21-33, Febuary 2012.

[8] Senthil Krishnamurthy and Raynitchka Tzoneva, "Investigation of the Methods for Single area and Multi area Optimization of a Power System Dispatch Problem," in International review of Electrical Engineering (IREE), vol. 7, no. 1, pp. 3600-3627, Febuary 2012.

[9] J.S. Dhillon , S.C. Parti and D.P. Kothari, "Stochastic economic emission load dispatch," Electric Power Systems Research, vol. 26, no. 3, pp. 179-186, April 1993.

[10] S. Krishnamurthy and R. Tzoneva, "Impact of Price Penalty Factors on the Solution of the Combined Economic Emission Dispatch Problem using Cubic Criterion Functions," 2012 IEEE Power and Energy Society General Meeting, San Diego, CA, pp. 1-9, 2012.

[11] S. Krishnamurthy and R. Tzoneva, "Comparative Analyses of Min-Max and Max-Max Price Penalty Factor Approaches for Multi Criteria Power System Dispatch Problem Using Lagrange's Method," 2011 International Conference on Power and Energy Systems, Chennai, pp. 1-7, 2011.

[12] S. Krishnamurthy and R. Tzoneva, "Comparative Analyses of Min-Max and Max-Max Price Penalty Factor Approaches for Multi Criteria Power System Dispatch Problem with valve point effect Using Lagrange's Method," 2011 International Conference on Power and Energy Systems, Chennai, pp. 1-7, 2011.

[13] Jacob Raglend, Sowjanya Veeravalli, Kasanur Sailaja, B. Sudheera, D.P. Kothari,"Comparison of AI techniques to solve combined economic emission dispatch problem with line flow constraints," in International Journal of Electrical Power \& Energy Systems, vol. 32, no. 6, pp. 592-598, July 2010.

[14] R.H.Bhesdadiya, et al., "Price Penalty factors Based Approach for Combined Economic Emission Dispatch Problem Solution using Dragonfly Algorithm," 2016 International Conference on Energy Efficient Technologies for Sustainability (ICEETS), Nagercoil, pp. 436-441, 2016.

[15] D. Hamza Zerigat, et al., "Solution of Combined Economic and Emission Dispatch problems using Galaxy-based Search Algorithm," J. Electrical Systems, vol. 9, no. 4, pp. 468-480, 2013. 
[16] Senthil Krishnamurthy, Raynitchka Tzoneva, "Impact of Price Penalty Factors on the Solution of the Combined Economic Emission Dispatch Problem using Cubic Criterion Functions," 2012 IEEE Power and Energy Society General Meeting, San Diego, CA, pp. 1-9, 2012.

[17] M. T. Tsai, and C.W. Yen, "An Improved Particle Swarm Optimization for Economic Dispatch with Carbon Tax Considerations," 2010 International Conference on Power System Technology, Hangzhou, pp. 1-6, 2010.

[18] T. Thakur, et al., "A Particle Swarm Optimization Solution to NO2 and SO2 Emissions for Environmentally Constrained Economic Dispatch Problem," 2006 IEEE/PES Transmission \& Distribution Conference and Exposition: Latin America, Caracas, pp. 1-5, 2006.

[19] R. Gnanadass, Narayana Prasad Padhy, K. Manivannan, "Assessment of available transfer capability for practical power systems with combined economic emission dispatch," in Electric Power Systems Research, vol. 69, no. 2, 267-276, May 2004.

[20] Hadi Hamedi, "Solving the combined economic load and emission dispatch problems using new heuristic algorithm," in International Journal of Electrical Power \& Energy Systems, vol 46, no. 1, pp. 10-16, March 2013.

[21] J. S. Dhillon, S. C. Parti and D. P. Kothari, "Multi-objective optimal thermal power dispatch," ACE '90. Proceedings of [XVI Annual Convention and Exhibition of the IEEE in India], Bangalore, India, pp. 136-140, 1990.

[22] Z. Ming, L. Xiaotong, Y. Fan, and T. Kuo, "The multiobjective optimization model of energy-efficient scheduling based on PSO algorithm," 2010 Asia-Pacific Power and Energy Engineering Conference, Chengdu, pp. 1-4, 2010.

[23] P. Venkatesh, R. Ganadass and Narayana Prasad Padhy, "Comparsion and Application of evolutionary programming techniques to combined economic emission dispatch with line flow constraints," in IEEE Transactions on Power Systems, vol. 18, no. 2, pp. 688-697, May 2003.

[24] Zwe-Lee Gaing and Rung-Fang Chang, "Security-Constrained economic scheduling of generation considering generator constraints," 2006 International Conference on Power System Technology, Chongqing, pp. 1-7, 2006.

[25] Hadi saadat, "Power Flow analysis," Milwaukee School of Engineering, McGraw-Hill Companies, 1999.

[26] J. Kennedy, R. C. Eberhart, "Particle swarm optimization," proceedings of ICNN'95 - International Conference on Neural Networks, Perth, WA, Australia, vol. 4, pp. 1942-1948, 1995

[27] Djilani Ben Attous, Yacine Labbi, "Particle Swarm Optimization based Optimal Power Flow for Units with NonSmooth Fuel Cost Functions," 2009 International Conference on Electrical and Electronics Engineering - ELECO 2009, Bursa, pp. I-377-I-381, 2009.

[28] Eberhart, R.C., and Shi, Y., "Comparing inertial weights and Constriction factor in particle Swarm optimization," Proceedings of the 2000 Congress on Evolutionary Computation. CECOO (Cat. No.00TH8512), La Jolla, CA, USA, vol. 1, pp. 84-88, 2000.

[29] Kennedy. J. and Eberhart, R. C., "Particle Swarm Optimazation," proceedings of ICNN'95 - International Conference on Neural Networks, Perth, WA, Australia, vol. 4, pp. 1942-1948, 1995.

[30] Mohammed Amine Meziane, Youssef Mouloudi, Bousmaha Bouchiba, Abdellah Laoufi, "Impact of inertia weight strategies in particle swarm optimization for solving economic dispatch problem," Indonesian Journal of Electrical Engineering and Computer Science (IJEECS), vol. 13, no. 1, pp. 377-383, January 2019.

[31] G. Sreenivasan, Dr. C. H .Saibabu, Dr. S. Sivanagaraju, "Solution of Dynamic Economic Load Dispatch (DELD) Problem with Valve Point Loading Effects and Ramp Rate Limits Using PSO," International Journal of Electrical and Computer Engineering (IJECE), vol. 1, no. 1, pp. 59-70, September 2011.

[32] Hossein Shahinzadeh, Sayed Mohsen Nasr-Azadani, Nazereh Jannesari, "Applications of Particle Swarm Optimization Algorithm to Solving the Economic Load Dispatch of Units in Power Systems with Valve-Point Effects," International Journal of Electrical and Computer Engineering (IJECE), vol. 4, no. 6, pp. 858-867, December 2014. 